doing so, parents are preparing their children for independent, safe navigation of the world around them.

\section{PATTERN OF CHILDHOOD INJURIES: FINDINGS FROM HOSPITAL BASED INJURY SURVEILLANCE SYSTEM IN OMAN}

${ }^{1}$ Amber Mehmood, ${ }^{1}$ Katherine A Ellen, ${ }^{1}$ Joseph Salami, ${ }^{2}$ Mohamed Al Yazidi, ${ }^{3} J e h a n$ Al Abri, ${ }^{1}$ Adnan A Hyder. ${ }^{1}$ Johns Hopkins Bloomberg School of Public Health; ${ }^{2}$ Ministry of Health, Oman; ${ }^{3}$ The Research Council of Oman

\subsection{6/injuryprev-2016-042156.918}

Background Globally, injuries cause death and disability for millions of children every year. Literature from high-income rapidly developing countries, such as the Arab Gulf states, on this burden is sparse. Realising this gap, a surveillance system was established in two hospitals of Oman. Data on childhood injuries was collected and analysed to better understand such injuries in the Arab Gulf States.

Methods Data was collected over a 6-month period in two large hospitals of Oman. All patients up to18 years who were admitted with a history of trauma between October 2014 and April 2015 were included. External cause and place of occurrence according to age and sex was analysed.

Findings $35 \%$ of all cases were paediatric (891/2549 cases) and of those, $69.3 \%$ were males. Children between $0-5$ years accounted for $53 \%$ of the study population. Most common external causes of injuries were falls (51\%), exposure to mechanical forces (20.4\%), and transport injuries (16.5\%) for all ages. Analysis by age revealed that falls accounted for $50.9 \%$ of injuries for ages $0-5$ years and $53.3 \%$ for 6-12 years. Transport injuries $(43.5 \%)$ were the most common cause for children 13-18 years, which were also more common in males (20\%) than females (8.4\%). Larger proportion of females $(13.5 \%)$ was injured by contact with heat and hot substances vs. males (6\%). Home was the place of injury for most children $0-5$ years $(86.4 \%)$ and $6-12$ years $(61.5 \%)$, whereas streets and highways were the most common place of injuries for age 13-18 years.

Conclusion Childhood injuries are a significant cause of hospital admissions in Oman. Significant age-related differences in cause of injury highlight the need for targeted interventions. Prevention of home-based falls and transport injuries must be a priority for all children. Additionally, road safety interventions and education must be the top agenda for young Omani males.

\section{NEW CRAZY GAME "RUSSIAN BIKER ROULETTE"}

1,2S Barbieri, ${ }^{2} \mathrm{~L}$ Omizzolo, ${ }^{3} \mathrm{R}$ El Mazloum, 'S Previato, ${ }^{1} \mathrm{C}$ Ravaioli, ${ }^{2} \mathrm{G}$ Vettore, ${ }^{1} \mathrm{M}$ Bergamini, ${ }^{3} \mathrm{R}$ Snenghi, ${ }^{2} \mathrm{P}$ Feltracco. ${ }^{7}$ Department Medical Science University Ferrara, Italy; ${ }^{2}$ Department Emergency Urgency Padova, Italy; ${ }^{3}$ Department Legal Medicine Padova, Italy

\subsection{6/injuryprev-2016-042156.919}

Background The spread of different games through the internet and via social networks is becoming a serious health problem that physicians and medical professionals have to deal with, and it is necessary for them to be aware of the risks those behaviours are connected to. Unintentional injuries are the leading cause of morbidity and mortality among child and teens and some Authors reports recommendation regarding safe practices to reduce injuries [1][2]. The "deadly new craze" involving bikers taking turns to cross a busy road without checking for cars is an unsafe practice visible in web videos.

Methods In this study we considered a particular case of bicycle accident related with a game proposed via web: the bike roulette challenge. We developed an appropriate, educational public health training program to understand the current characteristics of unintentional road traffic injury related with web challenges.

Results This case is about a 16 year-old male patient arrived alive to the hospital with thoracic and abdominal trauma. The length of stay was 18 days associated with serious surgical complications.

Conclusion In recent years is commonly possible to find strange, crazy, popular videos, via web with the intention to obtain in young population a good number of "likes". Bike roulette is a particular game described via web and is one of the new cause of trauma. Identifying biker roulette related injury in administrative data collections can be very problematic; the results of this apparently isolated case report can be used to research appropriate procedures and timely referrals of severe adolescent injury related to web games. School appropriate interventions have got the potential to reduce unintentional trauma related to these behaviours.

\section{GAMBELLA ETHIOPIA PRIMARY 5 SCHOOL VIOLENCE}

${ }^{1}$ Anteneh Tarekgen, ${ }^{1}$ Tigilalem Alemu, ${ }^{2}$ Kidist Bartholomeus, ${ }^{3}$ Ronald Lett. 'Gambella College of Health and Technology; ${ }^{2}$ WHO Geneva; ${ }^{3}$ Canadian Network for International Surgery, Vancouver

\subsection{6/injuryprev-2016-042156.920}

Background For decades in Gambella Ethiopia collective ethnic violence has been recurrent among the Nuer (Pastoralists), Anuak (Agriculturalist) \& Highlanders (Northern Ethiopians). The Anuak have been moved from their land to accommodate Indian, Saudi and Chinese agribusiness. Land pressures are augmented by refugees from the Southern Sudan. Injury and violence among grade 5 children growing up in this milieu was evaluated.

Methods The study was conducted in March 2013. Qualitative and quantitative data was collected from a randomised stratified sample. Ethical approval was obtained. Study population came from 21 Schools, (11 Urban, 2 Semi-urban, 10 rural), Pupils $\mathrm{N}=1674$ females 795).

Results Violence included physical attacks \& fights and hitting or stabbing with weapons. Attack Frequency: last 6 months 51.8\%, Fight 46.3\%, all Violence 57.5\%; Serious Injury $=16.7 \%$ (67.2\% Fracture; $28.6 \%$ Cuts). Validation was via School First Aid Records. Bullying episodes: 2/month (girls 67.2\%, boys 57.2\%); 10/month 14\%. Emotional Dimensions: social isolation in all: $8.51 \%$, no friends $15 \%$. Victimised 33\% no friends, $9.6 \%$ felt hopeless, 2.2\% suicidal, $\% 13$ sleep disorders 30\% absenteeism. Drug use among violence exposed: alcohol 38\%, tobacco $20 \%$ khat. 23\%, \& 21\% had initiated sexual activity. Children $(1 / 3)$ noted parents were unaware of their situation. Violence associations: female gender OR 2.35 (1.78-3.01), khat or Alcohol use OR 9.86 (6.16-15.77, sexual activity OR 2.16 (1.983.99). Family Support was protective.

Conclusions The prevalence of physical violence and bullying among Grade 5 children in Gambella is high. There was no variance between rural and urban settings. Injury was common; social consequences are severe Social misconduct was associated with violence; Family support was protective. Gambella Ethiopia has suffered from decades of collective ethnic based violence 